Journal of Social Sciences 8 (2): 120-125, 2012

ISSN 1549-3652

(C) 2012 Science Publications

\title{
Nutrition in Tertiary Education: Biological and Social Approaches
}

\author{
${ }^{1}$ Fragkiadakis, G.A., ${ }^{2}$ C. Papandreou and ${ }^{3}$ K. Gkouskou \\ ${ }^{1}$ Department of Nutrition and Dietetics, \\ Technological Education Institute of Crete, \\ School of Health and Welfare Professions, 72300 Siteia, Crete, Greece \\ ${ }^{2}$ Department of Medicine, \\ University of Crete School of Medical Sciences, \\ P.O. Box 2208, 71003 Heraklio, Crete, Greece \\ ${ }^{3}$ Institute of Molecular Biology and Biotechnology (I.M.B.B), \\ Foundation for Research and Technology-Hellas (FO.R.T.H), 70013 Heraklio, Crete, Greece
}

\begin{abstract}
Problem statement: Human Nutrition, a necessary component of health-education, studies the food-depended growth/maintenance of the human body. To approach what nutritionists will need to apply in the 21st century, we searched the literature for new syllabus-fields. Approach: We detected fields likely to play a significant and innovative role in university teaching of Human Nutrition; then tried a synthesis of biological and social approaches. Results: The courses connecting with the new era may be: (1) Molecular nutrition, focusing on nutrient related interactions at the gene, protein and metabolic levels. This includes nutritional biochemistry, concerned with the structure/function of nutrients; nutritional genomics, concerned with genome-nutrient interactions and including genetic variation on individual nutrient-requirements (nutrigenetics); nutritional metabolomics, concerned with interactions of metabolic pathways with nutrients; nutritional epigenomics, concerned with relationships between maternal nutrition and foetal development at the molecular level. (2) Nutritional systems biology, which integrates the molecular physiology of nutrition, from the intracellular to the inter-organ level, involving mathematical modelling. (3) Nutrition and behaviour, focusing on the relations among dietary patterns, hunger, satiety, mood and the central nervous system. (4) Community Nutrition, which is the promotion of health and prevention of nutritional diseases in the community level. Community Nutrition involves application of social science as well as psychological, cultural, economic and public health policy methods in groups/populations. (5) Social Nutrition, that focuses on the social, cultural, religious, economic and political aspects of eating and how these may influence people's nutrition and assists in overcoming the limitations in understanding all determinants of food intake. Conclusion/Recommendations: Current research in biological sciences brings Nutrition-Dietetics closer to biomedical sciences/applications and integrates our knowledge that must be included in the syllabuses/curricula of tertiary education Nutrition. On the other hand, social science approaches add significantly in these schemes, since genes and lifestyles do interact in human biology.
\end{abstract}

Key words: Human, university, studies, syllabus, cources

\section{INTRODUCTION}

Human Nutrition entails the study of the fooddepended growth, maintenance and repair of the body and comprises a necessary component of tertiary education in health. Human Nutrition science has received special attention over the past three decades, although adequate nutrition instruction is not always provided in universities or is not provided within designated Nutrition courses (Adams et al., 2006; Kafatos, 2009). Nutrition is coming to the fore as a major modifiable determinant of chronic disease, with scientific evidence increasingly supporting the view that alterations in diet have strong effects, both positive and negative, on health throughout all human life.

Most importantly, dietary adjustments may not only influence present health, but may determine whether or not an individual will develop such diseases

Corresponding Author: Fragkiadakis, G.A., Department of Nutrition and Dietetics, Technological Education Institute of Crete, School of Health and Welfare, Professions 72300 Siteia, Lasithi, Siteia, Crete, Greece 
as obesity; diabetes; cardiovascular disease; several forms of cancer; or osteoporosis and dementia much later in life. These chronic diseases are burdening the health in both the developed and the developing countries. Therefore, there is a need of community based recommendations for nutrition and social science approaches, in the prevention of chronic diseases. This could be achieved by scientists with high standards of tertiary education in several medical and paramedical sciences and professions, as internal medicine, nutrition-dietetics, nursing, midwifery, sociology and sports sciences The progress of Human Nutrition science depends on specific practices and innovative knowledge transmitted to students, through new courses, as well as research activities (Mann and Truswell, 2012; Gibney, 2009).

\section{MATERIALS AND METHODS}

Faculty resistance to changing university school curricula is a major barrier to overcome in the effort to expand nutrition education (Armstrong and Koffman, 2000). To overcome this resistance, it takes systemic proposals and initiatives; i.e., in USA, the Nutrition Academic Awards (NNA) program is an effort to spearhead innovations in nutrition education and in ways to integrate the subject into medical school curricula and medical practice (Pearson et al., 2001).

In order to approach and deduce what nutritionists and medics/paramedics will need to know in the 21st century, we searched in the literature and detected fields likely to play a significant and innovative role in teaching Human Nutrition. These fields represent new and innovative "dimensions" on teaching and research and their significance was evaluated both on the availability of convincing articles in the literature, as well as on the background of the 12 years teaching experience that the Department of Nutrition and Dietetics, T.E.I of Crete, has. As Dr. Lisa Hark puts it in a straight-forward way, summarizing the experience from the N.N.A funding of 21 USA medical schools to develop, implement, evaluate and disseminate nutrition curricula: the first lesson was/is "be creative and think out of the box when you are developing a nutrition curriculum" (Hark, 2006); this in our opinion can concern both course selection/design, as well as teaching strategies.

According to Feyerabend (1986), there are no methodological rules which are always to be used by scientists, since prescriptive scientific methods may limit their activities and hence restrict scientific progress. Consequently, the approach presented here is heuristic and not systematic, representing the vision, believes and even bias that we have on teaching the science of Nutrition and its applications. Within this vision, it is clear that the Social Science approaches have a significant role; the necessity of this dimension is already presented convincingly in the literature (Pelto and Freake, 2003).

\section{RESULTS AND DISCUSSION}

Presenting our literature and notions research, we propose some relevant courses to be adopted in future Nutrition-Dietetics syllabuses and curricula. This proposal is not based on the extent of the relevant literature, but rather on the educative and innovative relevance of the studies we mention, as well as on how convincing they were to us. The courses may include.

Molecular nutrition: Molecular nutrition (Elliott et al., 2007; Taylor, 2006; Sansone et al., 2007; Zeisel et al., 2005) is a discipline focusing on nutrient-related interactions at the gene, protein and metabolic levels. This includes nutritional biochemistry, concerned with the structure and function of well known or new nutrient chemical components; nutritional genomics, concerned with genome-nutrient interactions and including assessment of genetic variation on individual nutrient-requirements (nutrigenetics); nutritional metabolomics, concerned with multiple interactions of metabolic pathways with nutrients; nutritional epigenomics, concerned with the relationships between maternal nutrition and foetal development at the molecular level, i.e., the placental role and regulation of glucose transport to the foetus.

Molecular nutrition has been applied successfully the recent years, as i.e., to elucidate the mechanism for the regulation of sterol uptake in the intestine and intervene to reduce cholesterol uptake. In addition, the current technological conveniences that allow us to measure hundreds or thousands of metabolites in small samples of biological fluids or tissues, make it possible to assess the metabolic component of nutritional phenotypes and will allow individualized dietary recommendations (German et al., 2004).

Nutritional systems biology: Nutritional systems biology (Panagiotou and Nielsen, 2009) is a discipline that focuses on integrating the molecular physiology of nutrition, from the intracellular to the inter-organ level and involves mathematical (Reed et al., 2006) modelling and analysis. Model design translates the knowledge base into reactants and reactions and develops it into a network diagram with linked equations. Process diagrams have been used i.e., to map the interaction of adipocytes (lipid cells), hepatocytes (liver cells), skeletal muscle cells and pancreatic beta-cells in the metabolic syndrome (Kitano et al., 2004). 


\section{J. Social Sci., 8 (2): 120-125, 2012}

Functional food utilization in human diet: Functional foods are an emerging field in nutrition science due to their increasing popularity with health-conscious consumers. They are healthy foods claimed to have a health-promoting or disease-preventing property beyond the basic function of supplying nutrients. Functional food improve health not through offering calories but through regulating physiological human mechanisms, including intestine functions, prevention of inflammations, suppression of allergic reactions, nutritional support of immune-suppressed patients.

The general category of functional food includes processed food or foods fortified with healthpromoting additives, like "vitamin-enriched" products (Mermel, 2004). However, many of the Cretan- or Mediterranean-diet foods are functional and its beneficial effects occur due to their synergistic action (Fragkiadakis et al., 2012). Fermented foods with live cultures are considered as functional foods with probiotic benefits. Current developments in probiotic science, in addition to finding the most appropriate and efficient combination of probiotics/prebiotics, concerns three directions mainly: The subcutaneous administration of whole live probiotic micro-organisms; the development and administration of recombinant probiotic strains, to further enhance their beneficial properties (Ahmad et al., 2011).

Nutrition and behaviour: Nutrition and behaviour (Bathalon et al., 2000) is focusing on the relations among dietary patterns, behaviour factors, mood and the central nervous system. Of specific interest in this area are the behavioural aspects of overweight and obesity epidemics (Dababneh et al., 2011), since according to the World Health Organization (WHO) "obesity has reached epidemic proportions globally, with more than 1 billion adults overweight-at least 300 million of them clinically obese-and is a major contributor to the global burden of chronic disease and disability". This type of courses may also include the study of hunger and satiety control.

Furthermore, the nutrition and behaviour teaching axis can be interconnected with the previous mentioned molecular nutrition axis as i.e., analysis of proposed mechanisms by which Poly-Unsaturated Fatty Acids (PUFAs) are related with depression through their role in membrane fluidity or/and their influence on processes as neurotransmission and ion channel flow, formation of pro-inflammatory eicosanoids effecting neurotransmission (Papandreou et al., 2011). The relation of micronutrients with behaviour would be included in the teaching procedure i.e., the effect of iron deficiency on attention and learning processes in children, effects of sub-clinical vitamin deficiencies on behaviour, trace element analysis studies and violent behaviour (Worobey et al., 2006).

Maternal and child nutrition: This course would give knowledge of nutrition and its outcomes in women and their children, both in early and later life and how the nutritional exposures and/or diseases in the prenatal period and in early childhood are associated with obesity, or the occurrence of other chronic diseases (McGowan et al., 2008; Gkouskou et al., 2010). It would include pre-conceptual, antenatal and postnatal maternal nutrition, women's nutrition throughout their reproductive years and foetal, neonatal, infant, child and adolescent nutrition and their effects throughout life. Of course, this approach already exists in many Nutrition-Dietetics syllabuses, still molecular biology and epigenetics allow new integrated information to be added (Kaati et al., 2007).

Effect of environmental conditions on food properties: Environmental conditions can influence food properties (Karray-Bouraoui et al., 2010). Furthermore, recently, the nuclear reactor explosion at Fukushima Daiichi, Japan, caused widespread concern about the implications for humans, as the risk would be increased if radioactive contaminated foods are consumed. Radioactive particles can be transmitted through the food chain. The type of radioactive elements, the way these elements contaminate foods, the type of foods being contaminated, should be included in this course. Moreover, heavy metal contamination of food crops, vegetables, fishes should be included in this field. For example, mercury (a toxic heavy metal) can potentially contaminate fishes; and these food, known for their cardiovascular positive effects, may become harmful. Pollution of the environment seems to be involved in more diseases than we tend to believe in the past (Lee et al., 2006).

Future-dietetics ethics: The emphasis on this course must be given on projecting the values and ethical principles guiding the dietetics profession on emerging and future problems/controversies, as the utilization of "health claims" for the promotion of advanced nutritional supplements or novel food; internet based nutritional consultation; promotion of combined fitness, nutrition and beauty services. Students should learn the Code of Ethics for all dietetic practitioners and how to use it American Dietetic Association, 2009.

The dietetics practitioner should provide professional services with objectivity and with respect 
for the unique needs and values of individuals, practice dietetics based on evidence-based principles and current information and exercise professional judgment within the limits of his or her qualifications; collaborate with others, seek counsel, or makes referrals as appropriate. Again, elements of this approach already exist in many Nutrition-Dietetics curricula, however scientific progress, as i.e., the actual functional food benefits; the role of nutritional supplements in practise (Zadeh and Begum, 2011); the set of new questions concerning correct dietetic practises in the enteric and parenteric nutrition field (Ganzini, 2006), demand new views.

Community nutrition: Nutritional sciences are based on levels of organizational complexity, from molecules, through metabolism, to populations (Pelto and Freake, 2003). Nutrition-Dietetics application, as well as nutrition education of consumers, needs to address food preferences and sensory-affective factors; person related factors such as perceptions, beliefs, attitudes, meanings and social norms; and environmental factors (Contento, 2008). Community nutrition (Nnakwe, 2009) is the process of helping individuals and groups to develop healthy eating habits, in order to promote wellness and prevent the side effects of modern chronic disease. The goal of community nutrition is to educate people from all age groups, so that they adopt healthy eating habits.

Nutritionists work with many other health care professionals in promoting improved community nutrition. Their efforts emphasize a preventive approach in educating individuals in how a change in dietary habits will reduce the risk of illness. Concerning the promotion of health and prevention of nutritional diseases in the local community level (Badaruddoza and Kumar, 2011); it includes activities on nutrition education, health promotion, food hygiene and quality programs, food supplementation programs (i.e., fluoride, folic acid, iodine and iron), preventive programs, local policy analysis and development (Angelopoulos et al., 2009). Community nutrition involves application of social-science as well as psychological, cultural, agricultural, economic, clinical and public health policy methods for working with groups and populations (Nnakwe, 2009).

Healthy dietary patterns promotion: Patterns based on local diets paradigms and cultures. In example, the Cretan/Mediterranean Diet, which is basically the natural eating habits of the people of Crete during the 1960 s, is associated with the lowest known rates of chronic diseases in the world and the highest adult life expectancy (Simopoulos, 2001). The content of this diet, including high olive oil consumption, high consumption of legumes, high consumption of unrefined cereals, high consumption of fruits, vegetables and nuts, moderate consumption of dairy products (mostly as cheese and yogurt), moderate to high consumption of fish, low consumption of meat and meat products and moderate red wine consumption, can explain the health benefits it has (Fragkiadakis et al., 2012). The diversity and the variety of Mediterranean food cultures (Zubaida and Tapper, 2000) are an outstanding and underestimated sustainable development resource that has not yet been fully researched, systematically taught to university students, or effectively exploited economically. Nutritional tradition, culture and paradigms not only connect us with the past but show a "path" to re-test, in the recent days of economical, social and psychological crisis (Fragkiadakis et al., 2012).

The need of social science approaches: As stated by Pelto and Freake (2003): "The need to incorporate social science approaches in nutrition is apparent when the limitations of an exclusive focus on biological approaches are examined. For example, despite great advances in our knowledge about the metabolic and molecular pathways that govern energy metabolism and food intake, the incidence of obesity continues to rise to epidemic proportions. Biological knowledge, alone, is inadequate to understand this phenomenon and its consequences". Social, as well as economic, factors lead to particular nutritional outcomes (Pelto and Freake, 2003); consequently subjects as, cultural/nutritional perspectives (Satyavathi et al., 2012); political economy of food (Fang and Lee, 2009) and nutrition; children nutritional awareness; exercise; television and advertisement effects on food preferences; immigration effects; modern lifestyle effects, have to be researched and presented in tertiary education.

\section{CONCLUSION}

The American Society for Nutritional Sciences (ASNS) Graduate Nutrition Education Committee, suggests that three major challenges face the nutritional sciences: (a) to train doctoral students to be full and active participants in interdisciplinary research and discovery; (b) to achieve this goal while maintaining nutrition's unique academic identity and (c) fostering a cohesive academic community (Allen et al., 2002). As we enter the second decade of the 21 st century, nutrition is further recognized as a major parameter of human wellbeing, quality of life and disease prevention. The most exciting academic challenges and employment opportunities for nutritional sciences 
graduates interface with other disciplines (Allen et al., 2002): Current research in molecular nutrition, biochemistry, nutritional epidemiology and public health, brings the science of Nutrition-Dietetics closer to biomedical science and application and integrate our knowledge that must be included in the syllabuses and curricula of tertiary-education nutrition. On the other hand, Nutrition-Dietetics applications have to do with individual persons and with populations, thus, the social dimensions have to be taken into account and studied in depth. In addition to the dieticians, other specialists are and must further be involved in teaching various aspects of nutrition, including biochemists, pharmacists, pharmacologists, physiologists, psychologists, sociologists and of course medical doctors of various specialties (Bender, 1995). The selection of new courses and standardization of lessons descriptions, remains a challenge that may be faced knowledgeably, under the demand to discriminate the important and fruitful from the simply impressive and/or the sciantifically unproductive.

\section{REFERENCES}

Adams, K.M., K.C. Lindell, M. Kohlmeier and S.H. Zeisel, 2006. Status of nutrition education in medical schools. Am. J. Clin. Nutr., 83: 941S944S.

Ahmad, I., F. Ahmad and J. Pichtel, 2011. Microbes and Microbial Technology: Agricultural and Environmental Applications. 1st Edn., Springer, New York, ISBN: 1441979301, pp: 516.

Allen, L.H., M.E. Bentley, S.M. Donovan, D.M. Ney and P.J. Stover, 2002. Securing the future of nutritional sciences through integrative graduate education. J. Nutr., 132: 779-784.

Angelopoulos, P., G. Kourlaba, K. Kondaki, G.A. Fragiadakis and Y. Manios, 2009. Assessing children's diet quality in crete based on healthy eating index: The children studyhealthy eating index among children. Eur. J. Clin. Nutr., 63: 964969. DOI: 10.1038/ejcn.2009.10

Armstrong, E.G. and R.G. Koffman, 2000. Enhancing nutrition education through faculty development: From workshops to Web sites. Am. J. Clin. Nutr., 72: 877S-881S.

Badaruddoza, K. Gill and R. Kumar, 2011. Association of anthropometric and metabolic variables with cardiovascular disease among urban and rural origin Punjabi male population. Am. J. Applied Sci., $\quad$ 8: $\quad 953-961 . \quad$ DOI: 10.3844/ajassp.2011.953.961
Bathalon, G.P., K.L. Tucker, N.P. Hays, A.G. Vinken and A.S. Greenberg et al., 2000. Psychological measures of eating behavior and the accuracy of 3 common dietary assessment methods in healthy postmenopausal women. Am. J. Clin. Nutr., 71: 739-745.

Bender, D.A., 1995. Nutrition in the curriculum for health-care professionals. Environ. Manage. Health, 6: 14-16. DOI: $10.1108 / 09566169510090760$

Contento, I.R., 2008. Nutrition education: linking research, theory and practice. Asia Pac. J. Clin. Nutr., 17: 176-179.

Dababneh, B.F., J.M. El-Qudah and A.A. Al-Bakheit, 2011. Nutritional status and obesity among adults of Amman and Al-Balq'a governorates. Am. J. Agric. Biol. Sci., 6: 339-347. DOI: 10.3844/ajabssp.2011.339.347

Elliott, R., C. Pico, Y. Dommels, I. Wybranska, Hesketh and J. Keijer, 2007. Nutrigenomic approaches for benefit-risk analysis of foods and food components: Defining markers of health. Br. J. Nutr., 98: 1095-1100. DOI: 10.1017/S0007114507803400

Fang, C.H. and H.J. Lee, 2009. Food-related lifestyle segments in Taiwan: Application of the foodrelated lifestyle instrument. Am. J. Applied Sci., 6: 2036-2042. DOI: 10.3844/ajassp.2009.2036.2042

Feyerabend, P., 1986. Against Method: Outline of an Anarchistic Theory of Knowledge. 6th Edn., Verso, London, ISBN: 0902308912, pp: 339.

Fragkiadakis, G.A., G. Kyriakidis and K. Androulaki, 2012. Health claims and the mediterranean diet/food functional properties. Proceedings of the 8th Greek Legal and Medical Conference New Horizons in Law, Medicine and Science, Sept. 1723, Rhodes, Greece.

Ganzini, L., 2006. Artificial nutrition and hydration at the end of life: Ethics and evidence. Palliat. Support. Care, 4: 135-143. DOI: 10.1017/S1478951506060196

German, J.B., D.E. Bauman, D.G. Burrin, M.L. Failla and H.C. Freake et al., 2004. Metabolomics in the opening decade of the 21st century: Building the roads to individualized health. J. Nutr., 134: 27292732.

Gibney, M.J., 2009. Introduction to Human Nutrition. 2nd Edn., John Wiley and Sons, Chichester, ISBN: 1405168072, pp: 371.

Gkouskou, K.K., I.M. Vlastos, I. Hajiioannou, I. Hatzaki and M. Houlakis et al., 2010. Dietary habits of preschool aged children with tonsillar hypertrophy, pre- and post-operatively. Eur. Rev. Med. Pharmacol. Sci., 14: 1025-1030. 
Hark, L.A., 2006. Lessons learned from nutrition curricular enhancements. Am. J. Clin Nutr., 83: 968S-970S.

Kaati, G., L.O. Bygren, M. Pembrey and M. Sjostrom, 2007. Transgenerational response to nutrition, early life circumstances and longevity. Eur. J. Hum. Genetics, $\quad$ 15: 784-790. DOI: 10.1038/sj.ejhg.5201832

Kafatos, A., 2009. Is clinical nutrition teaching needed in medical schools? Ann. Nutr. Metab., 54: 129130. DOI: $10.1159 / 000210372$

Karray-Bouraoui, N., R. Ksouri, H. Falleh, M. Rabhi and C.A. Jaleel et al., 2010. Effects of environment and development stage on phenolic content and antioxidant activities of Mentha pulegium L. J. Food Biochem., 34: 79-89. DOI: 10.1111/j.17454514.2009.00303.x

Kitano, H., K. Oda, T. Kimura, Y. Matsuoka and M. Csete et al., 2004. Metabolic syndrome and robustness tradeoffs. Diabetes, 53: S6-S15. DOI: 10.2337/diabetes.53.suppl_3.S6

Lee, D.H., I.K. Lee, K. Song, M. Steffes and W. Toscano et al., 2006. A Strong dose-response relation between serum concentrations of persistent organic pollutants and diabetes 1999-2002. Diabetes Care, 29: 1638-1644. DOI: 10.2337/dc060543

Mann, J. and S. Truswell, 2012. Essentials of Human Nutrition. 4th Edn., Oxford University Press, ISBN: 0199566348, pp: 650.

McGowan, P.O., M.J. Meaney and M. Szyf, 2008. Diet and the epigenetic (re)programming of phenotypic differences in behavior. Brain Res., 1237: 12-24. DOI: 10.1016/j.brainres.2008.07.074

Mermel, V.L., 2004. Old paths new directions: The use of functional foods in the treatment of obesity. Trends Food Sci. Technol., 15: 532-540. DOI: 10.1016/j.tifs.2004.03.0054

Nnakwe, N.E., 2009. Community Nutrition: Planning Health Promotion And Disease Prevention. 1st Edn., Jones and Bartlett Learning, Sudbury, Mass., ISBN: 0763747602, pp: 401.

Papandreou, C., S.E. Schiza, G. Tsibinos, C. Mermigkis and C.M. Hatzis et al., 2011. Gluteal adipose-tissue polyunsaturated fatty-acids profiles and depressive symptoms in obese adults with Obstructive Sleep Apnea Hypopnea syndrome: A cross-sectional study. Pharmacol. Biochem. Behav., 98: 316-319. DOI: 10.1016/j.pbb.2011.01.016
Panagiotou, G. and J. Nielsen, 2009. Nutritional systems biology: Definitions and approaches. Ann. Rev. Nutr., 29: 329-339. DOI: 10.1146/annurevnutr-080508-141138

Pearson, T.A., E.J. Stone, S.M. Grundy, P.E. McBride and L.V. Horn et al., 2001. Translation of nutritional sciences into medical education: The nutrition academic award program. Am. J. Clin. Nutr., 74: 164-170.

Pelto, G.H. and C.H. Freake, 2003. Social research in an integrated science of nutrition: Future directions. J. Nutr., 133: 1231-1234.

Reed, M.C., H.F. Nijhout, M.L. Neuhouser, J.F. Baird and B. Shane et al., 2006. A mathematical model gives insights into nutritional and genetic aspects of folate-mediated one-carbon metabolism. J. Nutr., 136: 2653-2661.

Sansone, S.A., T. Fan, R. Goodacre, J.L. Griffin and N.W. Hardy et al., 2007. The metabolomics standards initiative. Nature Biotechnol., 25: 846848. DOI: $10.1038 /$ nbt0807-846b

Satyavathi, R.B., R.K. Anuradha, K.K. Reddy and R.B. Singh, 2012. Cultural and nutritional perspective of indian hunter-gatherers (kurichia tribe). Am. Med. J., 3: 1-7. DOI: 10.3844/amjsp.2012.1.7

Simopoulos, A.P., 2001. The mediterranean diets: What is so special about the diet of Greece? The scientific evidence. J. Nutr., 131: 3065S-3073S.

Taylor, C.F., 2006. Minimum reporting requirements for proteomics: A MIAPE primer. Proteomics, 6: 39-44. DOI: 10.1002/pmic.200600549

Worobey, J., B.J. Tepper and R.B. Karanek, 2006. Nutrition and Behavior: A Multidisciplinary Approach. 1st Edn., CAB, Wallingford, UK., ISBN: 0851996744, pp: 272.

Zadeh, S.S. and K. Begum, 2011. Nutritional supplements and its effect on quality of life and sleep. Am. Med. J., 2: 104-110. DOI: 10.3844/amjsp.2011.104.110

Zeisel, S.H., H.C. Freake, D.E. Bauman, D.M. Bier and D.G. Burrin et al., 2005. The Nutritional phenotype in the age of metabolomics. J. Nutr., 135: 16131616.

Zubaida, S. and R. Tapper, 2000. A Taste of Thyme: Culinary Cultures of the Middle East. 2nd Edn., Tauris Parke Paperbacks, London, New York, ISBN: 1860646034, pp: 302. 